\title{
屢 pubve†
}

HTTP://DX.DOI ORG/10.22256/PUBVET.V11N6.581-586

\section{Avaliação radiográfica da coluna cervical de bovinos que participaram de prova de laço em duplas}

\author{
Marisa Martire Pellegrini' ${ }^{1}$, Carolina Martire Pellegrini ${ }^{2}$, Marco Aurélio Gallo ${ }^{3}$, Roberto \\ Pimenta de Pádua Foz Filho ${ }^{4}$, André Luis do Vale De Zoppa ${ }^{5}$
}

${ }^{1}$ Graduanda do curso de Medicina Veterinária da Universidade Anhembi Morumbi - UAM. São Paulo - SP, Brasil. E-mail: marisa.pellegrini@gmail.com*

${ }^{2}$ Graduanda do curso de Medicina Veterinária da Universidade Anhembi Morumbi - UAM. São Paulo - SP, Brasil. E-mail: carolina27_pellegrini@hotmail.com

${ }^{3}$ Professor do curso de Medicina Veterinária da Universidade Anhembi Morumbi - UAM. São Paulo - SP, Brasil. E-mail: magallo@anhembi.br

${ }^{4}$ Professor do curso de Medicina Veterinária da Universidade Anhembi Morumbi-UAM. São Paulo-SP, Brasil. E-mail: rpfilho@anhembi.br

${ }^{5}$ Professor do curso de Medicina Veterinária da Universidade de São Paulo - USP. São Paulo - SP, Brasil. E- mail: alzoppa@usp.br

*Autor para correspondência:

RESUMO. Em um ambiente de prova real e de grande competitividade durante o campeonato nacional realizado no município de Avaré - SP em julho de 2016, obteve-se imagens radiográficas da coluna cervical de 56 bovinos, machos ou fêmeas sem raça definida, com peso médio de $250 \mathrm{~kg}$. As imagens foram obtidas antes e depois das provas, por meio de aparelho digital com os animais contidos em brete e em posição quadrupedal. Os critérios avaliados foram: malformação, fratura, luxação e alteração de posição das vértebras. As imagens foram estudadas por 2 avaliadores em separado e ambos não encontraram lesões anteriores ou posteriores à prova no grupo de animais estudados. Este resultado nos permite concluir que, nas condições deste experimento, não houve alteração na coluna cervical dos bovinos provocada pelo ato de laçar estes animais.

Palavras chave: Diagnóstico por imagem, exame radiográfico, lesão de coluna, rodeio

\section{Radiographic evaluation of cervical spine of cattle that participated in team roping}

ABSTRACT. In an environment of real competition and great competition during the national championship held in the city of Avaré-S.P. in July 2016, radiographic images of the cervical spine were obtained from 56 male and female bovine animals, with a mean weight of $250 \mathrm{~kg}$. The images were obtained before and after the event, using a digital device with the animals contained in stocks and in quadrupedal position. The evaluated criteria were: malformation, fracture, luxation and alteration of vertebra position. The images were studied by 2 separate evaluators and both did not find lesions before or after the event in the group of animals studied. This result allows us to conclude that, under the conditions of this experiment, there was no alteration in the cervical spine of the cattle caused by the lacing of these animals.

Keywords: diagnostic imaging, radiographic examination, spinal cord injury, rodeo

\section{Valoración radiográfica de la columna cervical de los bovinos que participaron de la prueba de lazo en pares}


RESUMEN. En un ambiente de prueba real y de gran competitividad durante el campeonato nacional realizado en el municipio de Avaré - SP en julio de 2016, se obtuvieron imágenes radiográficas de la columna cervical de 56 bovinos, machos o hembras sin raza definida, con peso medio de $250 \mathrm{~kg}$. Las imágenes se obtuvieron antes y después de las pruebas, por medio de un aparato digital con los animales sujetos en brete y en posición cuadrúpeda. Los criterios evaluados fueron: malformación, fractura, luxación y alteración de posición de las vértebras. Las imágenes fueron estudiadas por 2 evaluadores en separado y ambos no encontraron lesiones anteriores o posteriores a la prueba en el grupo de animales estudiados. Este resultado nos permite concluir que, en las condiciones de este experimento, no hubo alteración en la columna cervical de los bovinos provocada por el acto de lazarlos.

Palabras clave: Diagnóstico por imagen, examen radiográfico, lesión de columna, rodeo

\section{Introdução}

A ciência é a paixão disciplinada pela descoberta, pela vontade de dar sentido aos enigmas que nos são apresentados pelo mundo a nossa volta e dentro de nós, pela vontade de estabelecer extrapolações racionais a partir do que já sabemos ou que pelo menos acreditamos saber (Smith and Lino, 2006).

$\mathrm{O}$ uso de animais em modalidades culturais e esportivas tem suscitado discussões amplas no sentido de preservar a integridade e o bem-estar animal.

O conceito e os critérios de bem-estar animal e a avaliação do impacto observado em todos os animais que participam das diversas modalidades de "rodeios" tem sido uma preocupação constante das entidades que defendem os animais e das associações de criadores envolvidos nestes eventos ( $\underline{\text { ABTA, 2013). }}$.

Muitas provas são realizadas por Confederações, Federações, Associações de Raça e organizadores que já levam em conta as melhores práticas provendo boa infraestrutura de pistas, bom transporte e alojamento de animais, além de cuidados veterinários para com a saúde e bem-estar destes animais. Estes e tantos outros detalhes que fazem destas provas eventos sustentáveis. Organizadores de menor porte não tem o mesmo cuidado, algumas vezes por falta de recursos, mas muitas vezes por desconhecerem essas melhores práticas (MAPA, 2015).

Considerando o modelo brasileiro de criação de bovinos que é extensiva, os encarregados pelo rebanho devem fazer curativos nos animais no campo, para tanto os responsáveis laçam os animais a fim de imobilizar e realizar o tratamento adequado, fazendo do ato de laçar uma prática de várias regiões do país (ABQM, 2016).
Consciente da necessidade de uma abordagem científica quando o assunto envolve opiniões e "paixões", foi proposta a realização deste projeto de pesquisa em ambiente de prova real. O objetivo foi buscar elementos para responder perguntas frequentes relacionadas às lesões provocadas por algumas modalidades esportivas envolvendo animais. Neste caso específico: Ocorre lesão na coluna cervical dos animais laçados?

\section{Revisão da literatura}

Prova de laço

A prova do Laço em Duplas (Team Roping) tem como objetivo laçar a cabeça e as patas (membros pélvicos) de um bovino, de aproximadamente $200-250 \mathrm{~kg}$, no menor tempo possível. As provas são realizadas em pista de areia medindo em média $90 \mathrm{~m}$ de comprimento por $40 \mathrm{~m}$ de largura. $\mathrm{O}$ competidor que ocupa o lado esquerdo do brete é responsável por laçar a cabeça e o competidor do lado direito deve laçar os membros pélvicos. Após o animal ser laçado o juiz para o cronômetro e o bovino é liberado.

\section{Anatomia da coluna cervical}

\section{Vértebras}

Nos bovinos as vértebras cervicais não podem ser palpadas dorsalmente, mas sua posição pode ser detectada palpando-se a região do pescoço nas suas laterais. A identificação individual destes ossos é difícil, com exceção da asa do atlas (Dyce et al., 2004). As vértebras cervicais dos bovinos são mais curtas quando comparadas aos equinos e menores nas outras dimensões, e seus processos articulares são menores do que no cavalo apresentando uma lâmina óssea unindo as duas vértebras do mesmo lado. Os processos transversos das terceira, quarta e quinta vértebras são duplos. A parte dorsal é curta e espessa e se 
projeta em sentido caudal. A parte ventral projetase cranialmente e é mais laminar.

$\mathrm{Na}$ sexta vértebra sua parte cranial é uma lâmina grande, espessa, quadrilátera e quase sagital, dirigida ventralmente. $\mathrm{O}$ sétimo processo transverso é único, curto e espesso e sem forame transverso.

Os processos espinhosos são bem desenvolvidos e aumentam em altura no sentido crânio caudal e direcionados dorsocranialmente com exceção do último que é quase vertical e com cerca de $12 \mathrm{~cm}$ de altura (Sisson et al., 1986).

\section{Músculos cervicais, articulações e ligamentos das vértebras}

O ligamento da nuca consiste em um poderoso aparelho elástico com função de auxiliar os músculos extensores da cabeça e do pescoço. Ele é mais desenvolvido no bovino quando comparado ao equino. No bovino o funículo da nuca é claramente dividido em dois ramos laterais que são redondos em sua inserção no occipital tornando-se mais largo e plano em ambos os lados das espinhas vertebrais cobertas pelos músculos trapézio e romboide. Dirige-se para a parte mais alta da cernelha (terceira cervical) diminuindo e desaparecendo na região lombar. Os discos intervertebrais (fibrocartilagens) são mais espessos do que no equino. A fáscia cervical é abundante e bem desenvolvida no pescoço dos ruminantes, podendo ser evidenciado pelas pregas de tegumento que podem ser levantadas das estruturas subjacentes. A fáscia superficial está aderida à pele, enquanto a fáscia cervical profunda divide-se em: (1) a camada superficial da fáscia cervical profunda, que circunda a parte cervical do músculo trapézio e o músculo braquiocefálico e, (2) a camada profunda da fáscia cervical profunda, encontrada ventralmente às vértebras, e se insere nos processos transversos das vértebras e no músculo longo do pescoço, formando assim uma estrutura tubular que circunda a traqueia, o esôfago, as artérias carótidas comuns, as veias jugulares internas, os troncos vagossimpáticos e os nervos laríngeos recorrentes(Sisson et al., 1986).

\section{Lesões de coluna cervical}

\section{Fraturas e luxações}

As propriedades biomecânicas do sistema musculoesquelético dependem de numerosas associações integrais entre o osso, músculo, cartilagem e o tecido conjuntivo denso modelado.
Alterações nos ossos são influenciadas pela magnitude, direção, duração e tensão aplicada. A força pode ser suficiente para fraturar a estrutura ou pode alterar as suas relações tridimensionais com o resto da massa esquelética. Uma vez que as propriedades compressivas do osso são maiores que a as propriedades tensoras, a fratura óssea geralmente ocorre na tração (Banks and Rangel, 1986).

O impacto agudo é a causa mais frequente de fratura ou luxação de vértebra e não raro resulta em paralisia ou paresia. O resultado imediato do trauma provoca hemorragia, extravasamento de plasma dos capilares lesados, destruição de células e consequente redução do fluxo sanguíneo para a substância cinzenta da medula espinhal. Traumas nas vértebras ocasionando lesão na medula espinhal são mais comuns em animais jovens, ocorrem geralmente em colisões e quedas levando a uma hiperflexão ou hiperextensão da região cervical gerando fraturas ou luxações vertebrais (Jennings, 1984).

\section{Alterações compressivas}

As compressões podem ser agudas ou crônicas, e deve-se considerar que em ambos os casos o tecido nervoso não foi diretamente afetado. Incluíse nesta categoria as malformações do canal vertebral, alterações degenerativas dos processos articulares ocasionando fibrose periarticular ou exostose, hematoma epidural, calo ósseo originário de fratura de vértebra, osteomielite e ainda neoplasias. Frequentemente as compressões agudas provocam rápida necrose tecidual sendo que projetos de pesquisa demonstraram que a recuperação da compressão aguda é possível se as manobras de descompressão forem realizadas em até duas horas após o aparecimento das manifestações clínicas, por outro lado as compressões crônicas são toleradas mais facilmente devido a sua evolução mais lenta, permitindo que o tratamento da descompressão seja bem-sucedido se for realizado em até nove horas após o aparecimento dos sintomas (Jennings, 1984). As manifestações clínicas de fratura vertebral com compressão medular são agudas e geralmente não progressivas (Mills et al., 1988).

Albernaz (2010) estudando a região cervical de bezerros submetidos a manobras que simulavam provas de laço, não encontraram alterações clínicas nem tão pouco alterações nas imagens radiográficas na coluna cervical destes animais, 
concluindo que nas condições estabelecidas naquele experimento não houve alterações nos parâmetros clínicos e radiográficos dos bezerros submetidos a provas de laço, neste experimento em alguns exames radiográficos foi utilizada a técnica de mielografia. Estudos em bezerros de sete a sessenta dias de vida utilizando mielografia demonstraram a segurança da técnica em bovinos (Bueno, 2016).

\section{Processos infecciosos}

Infecções bacterianas nos corpos das vértebras e suas articulações, bem como no disco intervertebral e do espaço epidural podem ocorrer em bovinos e equinos. As vértebras cervicais, torácicas e lombares podem ser afetadas, sendo que em bovinos as vértebras lombares são as mais frequentemente envolvidas. A origem pode ser um processo infeccioso sistêmico ou originado por infecções localizadas próximas as vértebras (Jennings, 1984).

\section{Alterações de posição das vértebras}

Um grande número de alterações no posicionamento das vértebras foi descrito em bovinos e equinos: A escoliose relacionada a um desvio lateral da coluna, em bovinos geralmente ocorre associada a artrogrifose; Sifose (humpback) relacionada a um desvio dorsal da coluna toracolombar; Lordose (swayback) relacionada a um desvio ventral da coluna incluindo a coluna cervical e por fim o torcicolo (torticollis ou wryneck) relacionado a uma torção ou rotação do pescoço incluindo a vértebra cervical. O torcicolo pode ser adquirido ou congênito e neste último caso normalmente é acompanhado de outras deformidades (Jennings, $\underline{1984)}$

\section{Malformação das vértebras}

Malformação das vértebras com o estreitamento (estenose) do canal vertebral é afecção que pode ocorrer em bovinos e equinos. Pode acometer qualquer vértebra cervical (C1-C7) sendo mais comum entre $\mathrm{C} 3-\mathrm{C} 5$. A malformação tem origem multifatorial, porém acredita-se que um fator genético predisponente esteja presente. Somam-se a este fator genético situações de excesso de alimentação e/ou forças biomecânicas que atuam sobre o canal vertebral. Dentre as manifestações clínicas incluem-se ataxia, dismetria e falta de força nos membros, notadas inicialmente nos membros pélvicos. As diferentes malformações são diagnosticadas normalmente por meio de exames radiográficos ou ainda em necropsias (Jennings, 1984). Algumas anormalidades da coluna podem levar à instabilidade da coluna vertebral, sendo que dependendo do tamanho do comprometimento, podem gerar paresia, paraplegia e em casos mais graves, tetraparesia e tetraplegia (Mills et al., 1988).

\section{Material e Métodos}

Durante a realização $39^{\mathrm{a}}$ edição do Campeonato Nacional da Raça Quarto de Milha no município de Avaré no período de 19/07/2016 a 21/07/2016, acompanhou-se um grupo de bovinos que participaram das provas de laço em duplas (team roping).

A) População inicial: Um grupo de 80 bovinos (garrotes) sem raça definida, com idade média de dois anos, machos ou fêmeas e com peso médio de 250 quilos mensurado por fita de pesagem. Todos numerados para identificação.

B) Critério de exclusão: Animais que não foram utilizados durante as provas. Vinte e quatro animais foram radiografados em D0, mas não foram colocados nas provas e, portanto, não foram efetivamente laçados.

C) População escolhida: 56 animais que foram efetivamente laçados e submetidos aos dois exames radiográficos.

D) Técnica de avaliação: A população inicial (80 animais), foi submetida à exame radiográfico na véspera da prova (D 0). Os animais foram contidos em brete em posição quadrupedal possibilitando a obtenção de imagens radiográficas da coluna cervical nas posições látero-lateral e látero-lateral oblíqua com ângulo de aproximadamente $45^{\circ}$ no eixo dorsoventral, num total de 160 imagens obtidas. A população escolhida (56 animais) foi submetida ao exame radiográfico novamente no dia seguinte à prova $(\mathrm{D}$ $+1)$. A imagens foram obtidas utilizando o aparelho de RX digital: Leonardo DR-X com o DICIM PACS DR-X. Emissor: TOSHIBA 100HF $40-100 \mathrm{Kv}$ e até $30 \mathrm{mAs}$. O chassi foi colocado pelo lado direito do animal e o aparelho a uma distância de aproximadamente $90 \mathrm{~cm}$, o tempo de exposição foi de 2,1 mAs com $74 \mathrm{Kv}$.

E) Critério de avaliação: As imagens radiográficas digitais, gravadas em $\mathrm{CD}$ e convertidas em formato JPEG foram analisadas individualmente em tela de computador por dois avaliadores "cegos" (sem o conhecimento do 
resultado do outro avaliador), os resultados de cada análise individual foi tabulado para avaliação em 4 itens: a) malformação, b) fratura de vértebra, c) luxação de vértebra e d) mal posicionamento das vértebras.

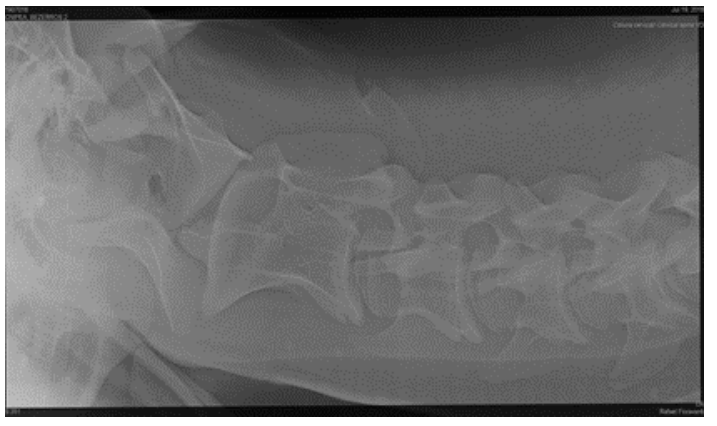

Figura 1. Exame radiográfico da coluna cervical (projeção lá tero-la teral) do be zerro $\mathrm{r}^{\rho} 15$ antes da prova.

Comparando-se as imagens obtidas antes e depois da prova, sob o ponto de vista de análise radiográfica, não foram observadas pelos 2 avaliadores quaisquer alterações radiográficas em

\section{Resultados}

$\mathrm{O}$ grupo de animais avaliados respeitando-se os critérios foi de 56 bovinos, radiografados antes e após a prova (Figura 1 e 2).

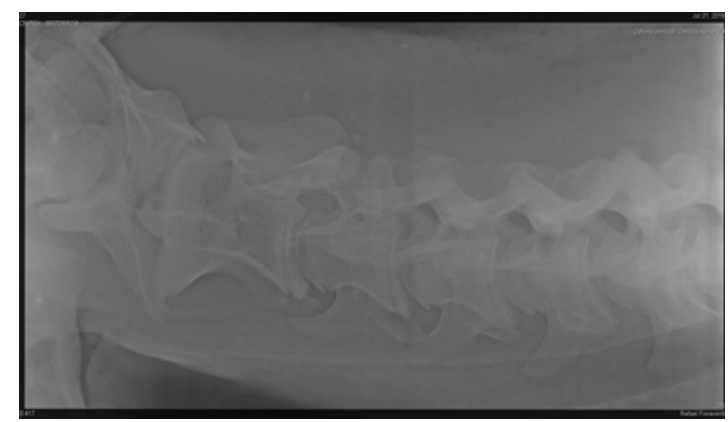

Figura 2. Exame radiográfico da coluna cervical (projeção látero-lateral) do bezerro $n^{\circ} 15$ após a prova.

vértebras cervicais do segmento $\mathrm{C} 1$ a $\mathrm{C} 5$, mesmo as de caráter congênito, que pudessem estar presentes (Quadro 1)

Quadro 1. Resultado da interpretação radiográfica realizada pelos dois avaliadores. São Paulo, 2016.

\begin{tabular}{lcc}
\hline Parâmetros avaliados & Avaliador 1 & Avaliador 2 \\
\hline Malformação & Nenhuma encontrada & Nenhuma encontrada \\
Fratura & Nenhuma encontrada & Nenhuma encontrada \\
Luxação & Nenhuma encontrada & Nenhuma encontrada \\
Alteração de posição & Nenhuma encontrada & Nenhuma encontrada \\
\hline
\end{tabular}

\section{Discussão}

O ambiente competitivo de uma prova de caráter nacional exigiu dos competidores máximo esforço no sentido de obter boas pontuações, portanto durante a realização desta pesquisa, todas as provas sendo elas amadoras ou profissionais foram realizadas em ambiente de competição acirrado.

A utilização de animais em modalidades culturais e esportivas tem suscitado discussões amplas no sentido de preservar a integridade e o bem-estar animal. Como salientaram Smith and Lino (2006) é necessário, aos seres humanos, incluir uma abordagem científica e disciplinada quando o assunto envolve opiniões e "paixões".

Comparando as imagens radiográficas obtidas antes de depois da prova, não foram observadas alterações na coluna cervical dos animais que foram laçados. A conformação da região do pescoço dos bovinos é forte e robusta, sendo observado um ligamento da nuca espesso e elástico com função de auxiliar os músculos extensores da cabeça e do pescoço. O fato de este ligamento ser mais desenvolvido no bovino quando comparado ao equino, e somando-se ao fato de que o funículo da nuca é dividido em dois ramos laterais que são mais largos e planos nos dois lados das espinhas vertebrais cobertas pelos músculos trapézio e romboide, proporciona boa estabilidade da região mesmo quando o pescoço é submetido a tração. Deve-se considerar ainda que os discos intervertebrais (fibrocartilagens) são mais espessos no bovino do que no equino, o que favorece a dissipação da tração (Banks and

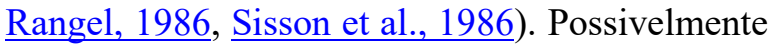
estes aspectos morfológicos foram determinantes para os resultados observados neste trabalho.

O número menor de animais radiografados no dia posterior a prova se deveu ao fato de que do grupo inicial (80 animais) somente 56 animais foram efetivamente laçados, os demais foram excluídos por não terem sido selecionados para a 
prova ou porque, durante a prova, o participante errou a laçada.

Não encontramos lesões nos animais avaliados neste trabalho. Estes resultados são semelhantes aos encontrados por Albernaz (2010) que estudaram a região cervical de bezerros submetidos a um procedimento que simulava provas de laço, neste trabalho, também não foram encontradas alterações clínicas nem tão poucas alterações nas imagens radiográficas da coluna cervical, concluindo que nas condições estabelecidas naquele experimento não houve alterações nos parâmetros clínicos e radiográficos dos bezerros submetidos a provas de laço.

Considerando a publicação de 2013 da britânica ABTA ressalta-se que as observações apresentadas no item laço em duplas cita genericamente o risco de lesão ou até morte do animal, porém sem a indicação de bibliografia científica que pudesse suportar tais afirmações.

Neste sentido projetos de pesquisas desenvolvidas em as áreas que envolvem "rodeios" devem ser encorajados e poderão trazer informações importantes no que diz respeito a alterações físicas provocadas por estas modalidades.

Considera-se ainda que os resultados obtidos neste projeto de pesquisa que avaliou animais que foram laçados em uma competição mostraram apenas a ausência de lesões radiograficamente detectáveis, porém temos consciência de que um maior número de projetos de pesquisa deve ser realizado no sentido de avaliar outros tecidos destes animais.

\section{Conclusão}

Considerando o grupo de animais estudados e as condições propostas neste estudo pôde-se concluir que não foram encontradas lesões nas vértebras cervicais provocadas pelas laçadas realizadas durante a prova, que pudessem ser detectadas por exame radiográfico.

\section{Referências Bibliográficas}

ABQM, Associação Brasileira de Criadores de Cavalo Quarto de Milha. O que você precisa saber sobre as provas de laço. Rua Dona Germaine Burchard, 355. São Paulo, SP. p.1, 2016.
ABTA. Animal Welfare guidelines, section five: managing the impact in focal species, ABTA Ltd, 30 park street, SE1 9EQ, London. p. 4045, 2013.

Técnica Permanente de Bem-estar Animal, Câmara Setorial de Equideocultura, Ministério da Agricultura. Pecuária e Abastecimento (MAPA), 2015

Albernaz, R. M. 2010. Aspectos clínicos e radiográficos da coluna cervical de bezerros submetidos à prova do laço. Revista Ciência Animal Brasileira, 10, 156-161.

Banks, W. J. \& Rangel, F. S. 1986. Histologia veterinária aplicada. Manole, São Paulo.

Bueno, G. M. 2016. Estudo mielográfico comparativo entre meios de contraste iopamidol e ioexol em bezerros. Faculdade de Ciências Agrárias e Veterinárias. Universidade Estadual Paulista, São Paulo.

Dyce, K. M., Wensing, C. J. G. \& Sack, W. O. 2004. Tratado de anatomia veterinária. Elsevier Brasil, São Paulo.

Jennings, P. B. 1984. The practice of large animal surgery. Saunders company, Philadelphia.

Manual de boas práticas para o bem estar animal em competições equestres Secretaria do Produtor Rural e Cooperativismo.

Mills, L. L., Dahlstrom, C. \& Hogan, P. M. 1988. Recognizing cervial spinal-cord compression in young calves. Veterinary Medicine, 83, 1181-1185.

Sisson, S., Grossman, J. D. \& Getty, R. 1986. Anatomia dos animais domésticos. Interamericana, Rio de Janeiro.

Smith, D. L. \& Lino, M. 2006. Por que mentimos: os fundamentos biológicos e psicológicos da mentira. Elsevier, Rio de Janeiro.

\section{Article History:}

Received 13 February 2017

Accepted 3 April 2017

Available on line 17 May 2017

License information: This is an open-access article distributed under the terms of the Creative Commons Attribution License 4.0, which permits unrestricted use, distribution, and reproduction in any medium, provided the original work is properly cited 